\title{
O curriculo como dispositivo orientador dos processos de ensino e de aprendizagem no ensino fundamental
}

The curriculum as a guiding device for teaching and learning processes in primary education

Dirléia Fanfa Sarmento ${ }^{1}$

Jardelino Menegat ${ }^{2}$

\section{Resumo}

As reflexões ora apresentadas são resultantes de uma pesquisa-ação colaborativa, cuja temática investigativa é a implantação da Base Nacional Comum Curricular (BNCC) na rede municipal de ensino de uma cidade pertencente à Região Metropolitana de Porto Alegre. Neste texto, fazemos um recorte dos encontros formativos com gestores, realizados na etapa Planejamento das ações, constituinte da abordagem teóricometodológica adotada. A ênfase dos encontros foi a reorganização curricular do Ensino Fundamental, tendo-se como referência a análise documental dos dispositivos legais que regulam a ação educativa e o diálogo com autores selecionados. Por meio da Técnica de Análise de Conteúdo, definimos dois eixos temáticos: a) o currículo segundo os dispositivos legais; e b) as relações entre currículo e os processos de ensino e de aprendizagem. Os principais achados do estudo apontam

${ }^{1}$ Doutora em Educação pela Universidade Federal do Rio Grande do Sul (porto Alegre/Brasil). Pós-doutorado em Educação pela Universidade do Algarve (Algarve/Portugal). Pós-doutorado em Educação pela Universidade Federal Fluminense (Rio de Janeiro/Brasil). Professora do Programa de Pós-graduação da Universidade La Salle (Canoas/Brasil). Pesquisadora do CNPq.

2 Doutor em Educação pela Universidade La Salle (Canoas/Brasil). Doutor em Administração pela Universidad de la Empresa, do Uruguai. Pós-doutorado em Educação pela Universidade Federal Fluminense, do Rio de Janeiro. Professor do Programa de Pós-graduação da Universidade Católica de Petrópolis (Rio de Janeiro/Brasil). Pesquisador do CNPq. Interfaces da Educ., Paranaíba, v.11, n.32, p. 489 - 514, 2020 
para a necessidade de: a) formação dos gestores e dos professores, focalizando o aprofundamento teórico e os dispositivos legais acerca do currículo; b) superação de uma visão reducionista acerca do currículo como mera listagem de conteúdos; c) partilha de possibilidades sobre a constituição da parte diversificada do currículo, articulada à base comum; d) apropriação, pelos atores educativos, do ideário do currículo estruturado com base no desenvolvimento de competências.

Palavras-chave: Direito à educação. BNCC. Currículo. Ensino. Aprendizagem.

EL CURRÍCULO COMO DISPOSITIVO ORIENTADOR DE LOS PROCESOS DE ENSEÑANZA-APRENDIZAJE

\section{Resumen}

Las reflexiones que se presentan son el resultado de una investigaciónacción colaborativa cuyo tema de investigación es la instauración de la Base Nacional Común Curricular (BNCC) en una Red Municipal de Enseñanza de una ciudad que pertenece a la Región Metropolitana de Porto Alegre. En este texto, hacemos un corte en los encuentros formativos con gestores, realizados en la etapa de Planificación de las acciones que constituyen el enfoque teórico-metodológico adoptado. E1 énfasis de los encuentros fue la reorganización curricular de la Enseñanza Fundamental, teniéndose como referente el análisis documental de las disposiciones legales que regulan la actividad educativa y el diálogo con los autores. Por medio de la Técnica de Análisis de Contenido, hemos definido cuatro ejes temáticos lo que se establecieron en base a la incursión analítica realizada: a) el currículo según las disposiciones legales; y b) las relaciones entre currículo y los procesos de enseñanza-aprendizaje. Los principales hallazgos encontrados en el estudio apuntan a la necesidad de: a) formación de los gestores y de los profesores, teniendo como foco la profundización teórica Interfaces da Educ., Paranaíba, v. 11, n.32, p. 489 - 514, 2020 
de las disposiciones legales acerca del currículo; b) superación de una visión reduccionista acerca del currículo como un mero listado de contenidos; c) el compartir las posibilidades sobre la constitución de las diversas partes del currículo articulada en una base común; d) apropiación, por los actores educativos, del ideario de currículo estructurado en base al desarrollo de competencias.

Palabras clave: Derecho a la educación. BNCC. Currículo. Enseñanza. aprendizaje.

\section{CURRICULUM AS A GUIDING DEVICE FOR TEACHING AND LEARNING PROCESSES}

\section{Summary}

The reflections presented here are the result of a collaborative action research whose investigative theme is the implementation of the Common National Curriculum Base (BNCC) in a Municipal Education System of a city belonging to the Porto Alegre Metropolitan Region.In this text, we make a cut in the formative meetings with managers, carried out in the Action Planning stage, constituting the theoretical-methodological approach adopted. The emphasis of the meetings was the curricular reorganization of the Elementary School, having as reference the documentary analysis of the legal devices that regulate the educational action and the dialogue with selected authors. Through the Content Analysis Technique, we define two thematic axes: a) the curriculum according to the legal provisions; and b) the relationships between curriculum and the teaching and learning processes. The main findings of the study indicate the need for: a) training of managers and teachers, focusing on the theoretical study and the legal provisions on the curriculum; b) overcoming a reductionist view of the curriculum as a mere listing of contents; c) sharing of possibilities regarding the constitution of the diversified part of the curriculum articulated to the Interfaces da Educ., Paranaíba, v.11, n.32, p. 489 - 514, 2020 
common base; d) appropriation by educational actors of the idea of the structured curriculum based on the development of competences.

Keywords: Right to education. BNCC . Curriculum. Teaching. Learning.

\section{Introdução}

A homologação da Base Nacional Comum Curricular (BNCC) tem suscitado reflexões acerca da revitalização do currículo escolar, sendo que a sua implantação é de caráter obrigatório no território nacional. A proposição de uma base nacional comum, enquanto uma das ações em prol da efetivação do direito à educação, atende ao preconizado em marcos legais nos âmbitos internacional e nacional.

O direito à educação (ONU, 1948; UNESCO, 1990; UNESCO, CONSED, Ação Educativa, 2001; OEI, 2012; UNESCO, 2015 a); b) pressupõe a efetivação do direito à aprendizagem. É necessário que, além da garantia de acesso e permanência na escola, seja assegurado que os estudantes tenham êxito no decorrer de seu itinerário formativo e desenvolvam competências que thes viabilizem a aprendizagem ao longo de suas vidas (UNESCO, 2015a, b).

A Declaração Mundial sobre Educação para Todos (UNESCO, 1990) enfatiza que: "Cada pessoa - criança, jovem ou adulto - deve estar em condições de aproveitar as oportunidades educativas voltadas para satisfazer suas necessidades básicas de aprendizagem”. Reforçando a proposição da Declaração Mundial sobre Educação para Todos, o Marco de Ação de Dakar assevera que a educação de qualidade está relacionada "às necessidades básicas de aprendizagem e enriquece a vida dos educandos e sua experiência global de vida" (UNESCO, CONSED, AÇÃO EDUCATIVA, 2001, p. 20).

O documento Metas Educativas 2021: a educação que queremos para a geração dos bicentenários, enfatiza que: "Talvez o desafio mais difícil para a região seja conseguir que todos os esforços dos países, para 
aumentar o nível educacional de sua população, se reflitam também em conquistas de aprendizagem de qualidade". (OEI, 2012, p. 27).

Dessa forma, conforme exposto, o direito à educação articula-se na possibilidade de cada pessoa ter êxito em termos de aprendizagem e ao seu pleno desenvolvimento. Nesse contexto, o currículo escolar é um dos fatores essenciais a ser considerado na oferta de educação de qualidade. Assim, não basta o estudante ter o seu acesso à escola garantido. É necessária, também, a existência de mecanismos que viabilizem a permanência e o êxito do estudante no contexto escolar. E um desses mecanismos é assegurar que o itinerário formativo resultante do currículo proposto seja significativo para os estudantes, traduzindo suas necessidades, características e expectativas.

Em consonância com os dispostivos internacionais supracitados, no contexto brasileiro o direito à educação está previsto na Constituição Federal (Brasil, 1988), no Estatuto da Criança e do Adolescente (1990), na Lei de Diretrizes e Bases da Educação Nacional (Brasil, 1996), nas Diretrizes Curriculares (Brasil, 2009, 2010, 2013), no Plano Nacional de Educação e na Base Nacional Comum Curricular (Brasil, 2017), dentre outros.

A ação no contexto escolar está pautada num ideário educativoformativo explicitado no Projeto Político-Pedagógico (ou Proposta Pedagógica), traduzindo-se na organização curricular. Ao se delinear um currículo, é preciso ter ciência de que, assim como em outros campos do conhecimento, no campo curricular coexistem vertentes teóricas distintas, sendo que cada qual acentua e se debruça sobre determinadas temáticas que trazem implicações para as orientações e proposições curriculares. (LOPES, MACEDO, 2010).

Feitas tais considerações, neste texto direcionamos nossa reflexão sobre os dados coletados por meio de uma pesquisa-ação colaborativa, cuja temática é a implantação da Base Nacional Comum Curricular (BNCC). Fazemos um recorte nas categorias relativas ao currículo 
escolar, compreendendo-o como um dispositivo orientador dos processos de ensino e de aprendizagem.

Em termos de estrutura, inicialmente introduzimos a temática a ser abordada. A seguir, contextualizamos o estudo, explicitando aspectos centrais da abordagem teórico-metodológica adotada. $\mathrm{Na}$ sequência, dedicamo-nos à análise e interpretação dos dados e, por fim, às considerações finais, retomando os principais achados do estudo.

\section{Contexto do estudo}

As reflexões ora apresentadas são decorrentes de uma pesquisaação colaborativa financiada pelo Conselho Nacional de Desenvolvimento Científico e Tecnológico (CNPq) cuja temática investigativa é a implantação da Base Nacional Comum Curricular na rede municipal de ensino de uma cidade localizada na Região Metropolitana de Porto Alegre, no estado do Rio Grande do Sul.

A pesquisa-ação colaborativa "articula a relação entre teoria e prática no processo mesmo de construção do conhecimento [...], possibilitando ao pesquisador a atuação efetiva sobre a realidade estudada" (MIRANDA; RESENDE, 2006, p. 514). Dessa forma, "o fato de teorizar forma parte do processo dialético de autotransformação e de mudança social: o processo através do qual os indivíduos reconstroem a si mesmos e ao mesmo tempo reconstroem sua vida social”. (CARR, 1996, p.15).

Em termos metodológicos, seguimos a estrutura sugerida por Kemmis e McTaggart (1992), os quais propõem quatro etapas a serem observadas no desenvolvimento da pesquisa-ação colaborativa: a) Diagnóstico-reconhecimento e fortalecimento de identidade de grupo; b) Planejamento das ações; c) Aplicação de estratégias de ação, processo de observação-registro; d) avaliação, reflexão e reorganização.

Neste texto, fazemos um recorte na etapa Planejamento das ações, abordando o trabalho desenvolvido com os gestores acerca das reflexões sobre a reorganização curricular do Ensino Fundamental, sendo que o escopo geral da pesquisa contempla outros atores educativos, além Interfaces da Educ., Paranaíba, v. 11, n.32, p. 489 - 514, 2020 
desses gestores. A centralidade desta etapa está no planejamento coletivo de ações a serem postas em curso, sendo tal planejamento desenvolvido no decorrer de um processo autorreflexivo (Monceau, 2005; Zeichner, Diniz-Pereira, 2005, Elliot, 2000) por meio de encontros formativos que se fundamentam na articulação entre teoria e prática, visando à açãoreflexão. Foram realizados nove encontros, com duração de três horas cada, no decorrer do ano de 2018, dos quais participaram vinte e dois representantes integrantes da equipe de gestão (direção, vice-direção, supervisão escolar e/ou orientação educacional) das treze escolas de Ensino Fundamental pertencentes à rede municipal de ensino.

Dentre algumas questões suscitadas pelo coletivo de protagonistas no decorrer desta etapa, destacamos: Quais as mudanças trazidas pela BNCC? A BNCC é o currículo escolar? Quais dispositivos legais precisamos retomar para reorganizar o currículo do Ensino Fundamental? Com a implantação do que estabelece a BNNC, o que é necessário mudar nos documentos que orientam a ação educativa na rede municipal? Quais as relações entre o currículo, o ensino e a aprendizagem?

Diante de tais questões, uma das ações desenvolvidas nos encontros formativos foi a análise documental dos seguintes documentos: a) Lei de Diretrizes e Bases da Educação Nacional (Brasil, 1996); b) Diretrizes Curriculares Nacionais para o Ensino Fundamental de 9 (nove) anos (Brasil, 2010), c) Base Nacional Comum Curricular (Brasil, 2017), e o Referencial Curricular Gaúcho (GOVERNO DO ESTADO RIO GRANDE DO SUL, 2018). Os registros dos aspectos centrais das reflexões no decorrer dos encontros foram realizados do Diário de Campo (BAUER; GASKELL, 2003; HESS, 2006).

Conforme assevera Pádua, o documento é "toda base de conhecimento fixado materialmente e suscetivel de ser utilizado para consulta, estudo ou prova." (PÁDUA, 2011, p. 69, grifo da autora). Ao utilizar documentos, é preciso ter presente que "A escolha dos documentos não é um processo aleatório, mas se dá em função de alguns Interfaces da Educ., Paranaíba, v.11, n.32, p. 489 - 514, 2020 
propósitos, ideias ou hipóteses". (GODOY, 1995, p. 23). Portanto, nossa escolha foi intencional, considerando-se que o conjunto de documentos selecionados deve ser observado na ação educativa. Além disso, a opção pela análise documental justifica-se pelo fato de que,

O uso de documentos em pesquisa deve ser apreciado e valorizado. A riqueza de informações que deles podemos extrair e resgatar justifica o seu uso em várias áreas das Ciências Humanas e Sociais porque possibilita ampliar o entendimento de objetos cuja compreensão necessita de contextualização histórica e sociocultural. (SÁ-SILVA, ALMEIDA, GUINDANI, 2009, p. 2).

Tendo presente questões suscitadas pelo coletivo de gestores, a incursão analítica coletiva nos referidos documentos e o diálogo com os autores que escolhemos para fundamentar as discussões, delineamos dois eixos temáticos que foram propostos, observando o que estabelece a Técnica de Análise de Conteúdo (BARDIN, 2011). Tais eixos são apresentados e aprofundados na próxima seção.

\section{Análise e interpretação dos dados}

Ao revisar o pensamento curricular brasileiro, Lopes e Macedo (2010, p. 16) salientam que tal pensamento não é homogêneo, havendo certa dificuldade mediante o "hibridismo de diferentes tendências [...] na definição do que vem a ser currículo". Nesse cenário, as autoras consideram que o campo do currículo é "um campo assinalado [...] mais pela diversidade orgânica do que pela uniformidade. Um campo em que diferentes discursos são reterritorializados [...], em resumo, um campo contestado em que se misturam influências, interdependências, rejeições" (idem, p. 47). Lopes e Macedo (2010, p.17-18) consideram o currículo

[...] como um campo intelectual: espaço em que diferentes atores sociais, detentores de determinados capitais sociais e culturais na área, legitimam determinadas concepções sobre a teoria do currículo e disputam entre si o poder de definir quem tem a autoridade na área. Trata-se de um campo capaz de influenciar propostas curriculares oficias, práticas pedagógicas nas escolas, a partir dos diferentes processos de recontextualização de seus

Interfaces da Educ., Paranaíba, v.11, n.32, p. 489 - 514, 2020 
discursos, mas que não se constitui dessas mesmas propostas e práticas. O campo intelectual do currículo é um campo produtor de teorias sobre currículos, legitimadas como tais pelas lutas concorrenciais nesse mesmo campo. (LOPES; MACEDO, 2010, p. $17-18)$.

Sacristán (2013, p. 20) evidencia a função reguladora do currículo, considerando que o mesmo incide sob os conteúdos, as práticas pedagógicas, os modos de estruturação escolar, e impõe "regras, normas e uma ordem que são determinantes". Dessa forma, esclarece o autor:

\begin{abstract}
Uma vez que admitimos que o currículo é uma construção onde se encontram diferentes respostas a opções possiveis, onde é preciso decidir entre as possibilidades que nos são apresentadas, esse currículo real é uma possibilidade entre outras alternativas. Aquilo que está vigente em determinado momento não deixa de ser um produto incerto, que poderia ter sido de outra maneira, e que pode ser diferente tanto hoje como no futuro. Não é algo neutro, universal e imóvel, mas um território controverso e mesmo conflituoso a respeito do qual se tomam decisões, são feitas opções e se age de acordo com orientações que não são as únicas possiveis. Definir quais as decisões tomar, após avaliá-las, não é um problema técnico (ou melhor, não é fundamentalmente uma tarefa técnica, pois as decisões tomadas afetam sujeitos com direitos, implicam explícita ou implicitamente opções a respeito de interesses e modelos de sociedades, avaliações do conhecimento e a divisão de responsabilidades.
\end{abstract}

Arroyo (2013) salienta a ideia do currículo enquanto um "território em disputa", considerando que "Na construção espacial do sistema escolar, o currículo é o núcleo e o espaço central mais estruturante da função da escola. Por causa disso, é o território mais cercado, mas normatizado".

Tendo presente tais pressupostos, nesta seção dedicamo-nos a apresentar as reflexões oriundas da análise dos dados coletados, os quais, conforme anunciado na seção anterior, foram categorizados em eixos temáticos. Passamos à reflexão acerca de cada um deles.

\title{
O curriculo segundo os dispositivos legais
}

As questões suscitadas pelo coletivo de gestores, descritas na introdução deste artigo, conduziram à reflexão sobre os pressupostos acerca do currículo escolar, tendo-se presente que no senso comum Interfaces da Educ., Paranaíba, v.11, n.32, p. 489 - 514, 2020 
prepondera a ideia dele se reduzir a um documento no qual consta a listagem de conteúdos conceituais a serem desenvolvidos no decorrer de um determinado espaço temporal.

Nos encontros formativos, revisitamos, por meio da análise documental, os dispositivos legais que normatizam, dentre outros aspectos, a organização curricular. Buscamos, com o coletivo de gestores, mapear os principais pressupostos que perpassam esses dispositivos, refletindo sobre as implicações de cada um deles para essa organização curricular. A ênfase recaiu sobre a articulação entre a base nacional comum e a parte diversificada do currículo.

Segundo as Diretrizes Curriculares do Ensino Fundamental (Brasil, 2010b, Art. 18),

O currículo do Ensino Fundamental com 9 (nove) anos de duração exige a estruturação de um projeto educativo coerente, articulado e integrado, de acordo com os modos de ser e de se desenvolver das crianças e adolescentes nos diferentes contextos sociais.

Nessa discussão entrou em cena a BNCC, como sendo um documento que estabelece normatizações somente sobre a constituição curricular da base comum. Portanto, já rompendo com a ideia desse documento ser o currículo propriamente dito e indicando que, como qualquer outro dispositivo, ele precisa ser compreendido e adequado a cada contexto.

Em termos organizativos, a BNCC estabelece um conjunto de competências a serem desenvolvidas ao longo da Educação Básica. Com relação ao Ensino Fundamental, são descritas competências específicas para cada área de conhecimento (Linguagens, Matemática, Ensino Religioso, Ciências Humanas e Ciências da Natureza) e habilidades específicas a serem desenvolvidas em cada componente curricular. Cada componente curricular possui uma estrutura interna própria, sendo apresentadas as habilidades e objetos de conhecimento a serem desenvolvidos. De acordo com o documento, a competência 
[...] é utilizada no sentido da mobilização e aplicação dos conhecimentos escolares, entendidos de forma ampla (conceitos, procedimentos, valores e atitudes). Assim, ser competente significa ser capaz de, ao se defrontar com um problema, ativar e utilizar o conhecimento construído. (BRASIL, 2017, p.16).

Igualmente, debruçamo-nos sobre o Referencial Curricular Gaúcho (Governo do Estado Rio Grande do Sul, 2018), documento específico do estado do Rio Grande do Sul, que deve ser "respeitado obrigatoriamente ao longo das respectivas modalidades, da Educação Infantil e do Ensino Fundamental, e que embasa o currículo das unidades escolares, no território estadual". (GOVERNO DO ESTADO RIO GRANDE DO SUL, 2018). Em termos de definições, o Referencial explicita a compreensão sobre aprendizagens essenciais; currículo; competência e território, que estão em consonância com o exposto em outros dispositivos legais.

Tal dispositivo indica que, na construção curricular, sejam observados o contexto $\mathrm{e}$ as características dos estudantes; a contextualização dos conteúdos curriculares para que se tornem significativos "com base na realidade do lugar e do tempo nos quais as aprendizagens se desenvolvem e são constituídas"; organização dos componentes curriculares de forma interdisciplinar e adoção de estratégias "mais dinâmicas, interativas e colaborativas em relação à gestão do ensino e da aprendizagem"; metodologias e estratégias didático-pedagógicas diversificadas; situações e procedimentos para motivar e engajar os estudantes nas aprendizagens; procedimentos de avaliação formativa que considerem "contextos e as condições de aprendizagem, tomando tais registros como referência para melhorar o desempenho da instituição escolar, dos professores e dos estudantes"; utilização de "recursos didáticos e tecnológicos para apoiar o processo de ensinar e aprender", dentre outros. (GOVERNO DO ESTADO RIO GRANDE DO SUL, 2018).

Em consonância com o exposto no documento Metas Educativas 2021: a educação que queremos para a geração dos bicentenários, entendemos que:

Interfaces da Educ., Paranaíba, v.11, n.32, p. 489 - 514, 2020 
Um currículo significativo é aquele que se conecta com os interesses dos alunos e com o seu modo de viver, que se adapta a seus ritmos de aprendizagem, que estabelece de forma permanente a relação entre o que foi aprendido e as experiências que os alunos vivem fora da escola. Além disso, um currículo será significativo se permitir a participação do alunado e o trabalho em grupo, que incorpora, de forma habitual, a utilização das tecnologias da informação, inclui, de forma relevante e equilibrada, o desenvolvimento da educação artística e desportiva e cuida para que todos os seus alunos se sintam bem dentro da instituição educacional e que possam aprender. (OEI, 2012, p.38).

Em termos organizativos, o Referencial adota a mesma estrutura da BNCC, apresentando destaques em cada habilidade, seja em termos de acréscimo, supressões e/ou adequações de forma a contemplar as características regionais.

No nosso entender, as competências gerais (sejam por área ou componente) quanto às habilidades descritas tanto na BNCC quanto no Referencial Curricular Gaúcho, necessitam ser traduzidas, interpretadas e reescritas pelos professores na elaboração dos Planos de Estudos devido à amplitude das mesmas. Da mesma forma, para haver coerência com o conceito de competência adotado nos referidos documentos, as atitudes e valores a serem desenvolvidos seja em cada ano ou ao longo de um determinado espaço temporal, precisam ser explicitadas.

Isso requer que cada Rede de Ensino viabilize aos professores espaços e tempos para estudo, discussões e elaboração coletiva desses Planos que se desdobrarão, posteriormente, em Planos de Trabalho e Planos de Aula. Essa construção coletiva contribui para a existência de uma identidade dentro da Rede, viabilizando

[...] a intercomunicação constante entre [...] profissionais que comungam dos mesmos propósitos e ideais, no sentido de construírem em conjunto uma ação [...] em vista de continuamente trocarem ideias a respeito de como podem se apoiar reciprocamente para realizarem os objetivos comuns. (LÜCK, 2000, p. 21).

$\mathrm{Na}$ reflexão acerca da obrigatoriedade de uma base comum nacional, trouxemos nos encontros formativos reflexões de autores, tais Interfaces da Educ., Paranaíba, v.11, n.32, p. 489 - 514, 2020 
como Dourado (2013); Belmonte Machado e Lockmann (2014); Cóssio (2014); Alves (2014); Süssekind (2014); Gontijo (2015); Silva, Neto e Vicente (2015); Lima Verde (2015); Sousa (2015); Abramowicz, Cruz e Moruzi (2016); Macedo (2014, 2015, 2016); Cunha e Lopes (2017); Marsiglia et ali (2017); Carvalho, Silva e Del Boni (2017), os quais apontam para a complexidade da proposição de um currículo comum, considerando-se os inúmeros fatores que intervêm na ação educativa; as assimetrias regionais, socioculturais e econômico-financeiras; a descontinuidade de políticas públicas e as questões que incidem sobre o financiamento da educação.

Se a proposição de uma base nacional comum curricular é considerada complexa, o que dizer acerca do previsto por Arroyo (2013, p.13), de que "Caminhamos para a configuração de um currículo não só nacional, mas internacional, único, avaliado em parâmetros únicos". Com os processos de globalização, de internacionalização e de perspectivas sobre a formação de um cidadão global, talvez esta não seja uma realidade tão distante.

Interessante destacar que, em tais dispositivos, é dado ênfase na constituição e na organização curricular, havendo uma lacuna no que se refere à clarificação de seu conceito. É possível constatar nas Diretrizes Curriculares Nacionais para o Ensino Fundamental de 9 (nove) anos (Brasil, 2010b) uma tentativa de definição quando apresentam, em seu Artigo $9^{\circ}$, que:

O currículo do Ensino Fundamental é entendido, nesta Resolução, como constituído pelas experiências escolares que se desdobram em torno do conhecimento, permeadas pelas relações sociais, buscando articular vivências e saberes dos alunos com os conhecimentos historicamente acumulados e contribuindo para construir as identidades dos estudantes.

Em seguida, nos três parágrafos do referido artigo, é explicitada a compreensão de que as experiências escolares se efetivam por meio das ações educativas, contemplando "a parte explícita do currículo, bem como os que também contribuem, de forma implícita, para a aquisição de Interfaces da Educ., Paranaíba, v.11, n.32, p. 489 - 514, 2020 
conhecimentos socialmente relevantes" (BRASIL, 2010b, Art. $9^{\circ}, \S 2^{\circ}$ ). Tais conhecimentos

[...] são aqueles que as diferentes instâncias que produzem orientações sobre o currículo, as escolas e os professores selecionam e transformam a fim de que possam ser ensinados e aprendidos, ao mesmo tempo em que servem de elementos para a formação ética, estética e política do aluno. (BRASIL, 2010b, Art. $\left.9^{\circ}, \S 3^{\circ}\right)$.

Entretanto, apesar de a ideia introdutória do referido artigo indicar uma possivel definição de currículo, o restante do texto remete à sua constituição. Parece ser mais importante nos dispositivos analisados estabelecer normas e determinados conteúdos a serem observados na constituição curricular do que suscitar a discussão do que se entende por currículo e quais as intencionalidades formativas com tais proposições.

No decorrer dos encontros formativos, dentre as reflexões partilhadas pelo coletivo de gestores, em termos de síntese, destacamos: a) a constatação de possuírem conhecimento incipiente acerca do currículo, e devido a isso, desconhecerem a existência de teorias curriculares (assim como existem teorias sobre a aprendizagem, por exemplo); b) a fragilidade da formação, tanto no âmbito do Curso de Pedagogia quanto na formação continuada, onde as abordagens acerca das questões curriculares não são aprofundadas e, por vezes, são até negligenciadas; c) a precária familiaridade com os dispositivos legais e a existência de um olhar panorâmico em relação à BNCC e ao Referencial Curricular Gaúcho; d) o estranhamento com a parte diversificada do currículo, sendo que em suas trajetórias essa dimensão não se constituiu em foco de análise; e) a necessidade de aprofundar o que está na proposta da BNCC e no Referencial Curricular Gaúcho para, em parceria com o coletivo de professores que atuam na Rede, estudar tais dispositivos e subsidiá-los para participarem, colaborativamente, da construção curricular; f) a complexidade de uma proposição curricular, tendo-se presente que ela (de forma explícita ou implícita) sempre traduz determinada concepção sobre o currículo que, por sua vez, assenta-se Interfaces da Educ., Paranaíba, v.11, n.32, p. 489 - 514, 2020 
em determinada vertente teórica; e g) a importância do currículo enquanto um dispositivo tradutor de um ideário de educação e formação humana que inspira e norteia a ação educativa.

Tais constatações nos mobilizaram a questionar o papel da equipe de gestão, enquanto dinamizadora da gestão administrativa e pedagógica da escola. Ora, como o conjunto de professores de uma escola poderá assumir um projeto coletivo, de forma qualificada, se aqueles que estão à frente da gestão carecem de conhecimentos essenciais?

Obviamente, vários encontros formativos ainda serão necessários com o coletivo de gestores (e também com os professores) para haver um avanço nas questões por eles apontadas. Contudo, consideramos o fato dos gestores se conscientizarem das suas limitações e se mobilizarem ao aprofundamento teórico-metodológico como indicativos resultantes do processo reflexivo, que é um dos objetivos perseguidos pela adoção da abordagem teórico-metodológica que fundamenta a pesquisa açãocolaborativa.

Por outro lado, os gestores chegaram à conclusão de que se há mudanças na organização curricular torna-se necessário revitalizar o Projeto Político-Pedagógico, pois ambos estão interacionados. E, havendo proposições diferenciadas (por exemplo) em relação à expressão dos resultados de aprendizagem por meio da avaliação, o Regimento Escolar precisa ser revisto. Com base nisso, constatamos que os gestores começaram a perceber a dimensão sistêmica entre os dispositivos legais externos e internos à escola.

\section{As relações entre currículo e os processos de ensino e de aprendizagem.}

O currículo, compreendido como um dispositivo em constante evolução e mudança, vivifica-se nas relações cotidianas num movimento dialético em que operam os currículos formal, real e oculto. Ao traduzir um ideário de educação e formação humana o currículo sinaliza, dentre outras dimensões, para as aprendizagens consideradas essenciais a Interfaces da Educ., Paranaíba, v.11, n.32, p. 489 - 514, 2020 
serem desenvolvidas ao longo de um itinerário formativo dos estudantes. Nesse sentido, conforme Sacristán (2013, p. 23):

\begin{abstract}
A importância fundamental do currículo para a escolaridade reside no fato de que ele é a expressão do projeto cultural e educacional que as instituições dizem que irão desenvolver com os alunos (e para eles), aquilo que é considerado adequado. Por meio desse projeto institucional são expressos forças, interesses ou valores e preferências da sociedade, de determinados setores sociais, das famílias, dos grupos políticos etc.
\end{abstract}

Assim, é preciso um olhar crítico sobre os modos de seleção, sobre quem são os responsáveis por definir as aprendizagens e experiências consideradas essenciais e sobre as intencionalidades presentes na inclusão/exclusão das mesmas, tendo em vista o perfil de pessoa, de sociedade e de mundo que serão (con)formados a partir dessa proposição. Desse ponto de vista, "A questão básica por detrás de qualquer planejamento ou proposta curricular é sempre quais experiências educacionais vale a pena proporcionar em nossas instituições educacionais". (CONTRERAS, 2013, p. 459). Nesse sentido, retomamos o exposto na Declaração Mundial sobre Educação para Todos (UNESCO, 1990) quando o documento salienta como um dos desafios da escola a satisfação das necessidades básicas de aprendizagem dos estudantes. Explica o documento:

\footnotetext{
Essas necessidades compreendem tanto os instrumentos essenciais para a aprendizagem (como a leitura e a escrita, a expressão oral, o cálculo, a solução de problemas), quanto os conteúdos básicos da aprendizagem (como conhecimentos, habilidades, valores e atitudes), necessários para que os seres humanos possam sobreviver, desenvolver plenamente suas potencialidades, viver e trabalhar com dignidade, participar plenamente do desenvolvimento, melhorar a qualidade de vida, tomar decisões fundamentadas e continuar aprendendo. A amplitude das necessidades básicas de aprendizagem e a maneira de satisfazê-las variam segundo cada país e cada cultura, e, inevitavelmente, mudam com o decorrer do tempo. (UNESCO, 1990).
}

Se os estudantes são concebidos como sujeitos de direitos e que a efetivação do direito à educação pressupõe o direito à aprendizagem, o currículo precisa explicitar em sua proposição tais concepções. Ao Interfaces da Educ., Paranaíba, v.11, n.32, p. 489 - 514, 2020 
abordar o direito à educação, o Parecer CNE/CEB n $\mathrm{n}^{\circ} 7 / 2010$, que versa sobre as Diretrizes Curriculares Nacionais Gerais para a Educação

Básica (Brasil, 2010a), assevera que:

Compreender e realizar a educação, entendida como um direito individual humano e coletivo, implica considerar o seu poder de habilitar para o exercício de outros direitos, isto é, para potencializar o ser humano como cidadão pleno, de tal modo que este se torne apto para viver e conviver em determinado ambiente, em sua dimensão planetária. A educação é, pois, processo e prática que se concretizam nas relações sociais que transcendem o espaço e o tempo escolares, tendo em vista os diferentes sujeitos que a demandam. Educação consiste, portanto, no processo de socialização da cultura da vida, no qual se constroem, se mantêm e se transformam saberes, conhecimentos e valores. (BRASIL, 2010).

$\mathrm{Na}$ mesma linha reflexiva, as Diretrizes Curriculares Nacionais para o Ensino Fundamental (Brasil, 2010) retomam a proposição constitucional do direito à educação, evidenciando em seu Artigo $5^{\circ}$ que:

O direito à educação, entendido como um direito inalienável do ser humano, constitui o fundamento maior destas Diretrizes. A educação, ao proporcionar o desenvolvimento do potencial humano, permite o exercício dos direitos civis, políticos, sociais e do direito à diferença, sendo ela mesma também um direito social, e possibilita a formação cidadã e o usufruto dos bens sociais e culturais.

$\S 1^{\circ}$ O Ensino Fundamental deve comprometer-se com uma educação com qualidade social, igualmente entendida como direito humano.

$\S 2^{\circ}$ A educação de qualidade, como um direito fundamental, é, antes de tudo, relevante, pertinente e equitativa.

A educação de qualidade é compreendida sob a perspectiva da qualidade social, tendo-se como compromisso central a aprendizagem, tal como se constata a seguir:

O conceito de qualidade na escola, numa perspectiva ampla e basilar, remete a uma determinada ideia de qualidade de vida na sociedade e no planeta Terra. Inclui tanto a qualidade pedagógica quanto a qualidade política, uma vez que requer compromisso com a permanência do estudante na escola, com sucesso e valorização dos profissionais da educação. Trata-se da exigência de se conceber a qualidade na escola como qualidade social, que se conquista por meio de acordo coletivo. Ambas as

Interfaces da Educ., Paranaíba, v.11, n.32, p. 489 - 514, 2020 
qualidades - pedagógica e política - abrangem diversos modos avaliativos comprometidos com a aprendizagem do estudante, interpretados como indicações que se interpenetram ao longo do processo didático pedagógico, o qual tem como alvo o desenvolvimento do conhecimento e dos saberes construídos histórica e socialmente. (BRASIL, CNE/CEB, 2010).

Ao estabelecer uma base nacional comum, a BNCC "define o conjunto orgânico e progressivo de aprendizagens essenciais que todos os alunos devem desenvolver ao longo das etapas e modalidades da Educação Básica" (BRASIL, 2017, p. 7, grifo do documento). O documento faz alusão aos direitos de aprendizagem e desenvolvimento, os quais se traduzem sob a forma de competências e habilidades a serem desenvolvidas. De acordo com a BNCC:

Ao adotar esse enfoque, a BNCC indica que as decisões pedagógicas devem estar orientadas para o desenvolvimento de competências. Por meio da indicação clara do que os alunos devem "saber" (considerando a constituição de conhecimentos, habilidades, atitudes e valores) e, sobretudo, do que devem "saber fazer" (considerando a mobilização desses conhecimentos, habilidades, atitudes e valores para resolver demandas complexas da vida cotidiana, do pleno exercício da cidadania e do mundo do trabalho), a explicitação das competências oferece referências para o fortalecimento de ações que assegurem as aprendizagens essenciais definidas na BNCC. (BRASIL, 2017, p.13, grifo do documento).

Dessa forma, o currículo precisa contemplar tanto conteúdos conceituais quanto conteúdos procedimentais e conteúdos atitudinais, sendo tais conteúdos trabalhados de forma articulada. (ZABALA; ARNAU, 2010).

A centralidade do aprender também é reiterada no Referencial Curricular Gaúcho quando tal dispositivo estabelece como principios orientadores do currículo o direito de aprender; a contextualização e sistematização dos conceitos articulados com processos de aprendizagem; a proposição de atividades diversificadas pelo professor com foco no desenvolvimento de competências; o protagonismo estudantil no processo educativo e o prazer de aprender. (GOVERNO DO ESTADO DO RIO GRANDE DO SUL, 2018, Artigo $4^{\circ}$ ).

Dentre tantos desafios que se colocam ao professor, na ótica dos gestores, acentua-se a organização curricular com base no Interfaces da Educ., Paranaiba, v.11, n.32, p. 489 - 514, 2020 
desenvolvimento de competências. Tal organização requer um olhar diferenciado por parte dos professores, em relação aos modos de se planejar e efetivar a ação educativa. Em outras palavras, no entender dos gestores, não basta existir uma organização curricular por competências, é necessário que o planejamento, o ensino, as situações de aprendizagem e a avaliação estejam em consonância com este ideário. Para tanto, os professores precisam ter espaços e tempos para a reflexão sobre o significado de uma ação educativa pautada pelo desenvolvimento de competências. Assim,

[...] se o currículo se relaciona com o ensinar e a aprendizagem nas instituições educacionais, ele obrigatoriamente também se relaciona com a formação dos professores, com o que se produz dentro delas e cujo fim é favorecer a aprendizagem dos estudantes. (IMBERNÓN, 2013, p. 494).

Vale ressaltar que a ação educativa com base no desenvolvimento de competências não é algo novo, pois já havia esta indicação nos Parâmetros Curriculares Nacionais (PCNs). Contudo, diferente dos PCNs, o estabelecido pela BNCC é de cunho obrigatório, o que significa que esta lógica deve se fazer presente nas práticas pedagógicas.

Igualmente, considerando os professores como protagonistas essenciais na construção curricular, além da tradução do que preconizam os dispositivos legais sobre a base comum, constitui-se um desafio à sua participação na proposição da parte diversificada deste currículo. Tal proposição é uma das responsabilidades dos sistemas de ensino e das escolas "de modo a complementar e enriquecer o currículo, assegurando a contextualização dos conhecimentos escolares em face das diferentes realidades". (BRASIL, 2010b, Artigo 11, §3º).

Esta parte diversificada é que irá assegurar a observação das características de cada região, de cada rede de ensino e de cada contexto educativo, onde suas mantidas se encontram inseridas e, dentro desse contexto educativo, as peculiaridades dos sujeitos aprendentes que ali se encontram. Essa ideia é ressaltada na BNCC (Brasil, 2017, p. 18): 
Muitas escolas públicas e particulares também acumularam experiências de desenvolvimento curricular e criação de materiais de apoio ao currículo, assim como instituições de ensino superior construíram experiências de consultoria e de apoio técnico ao desenvolvimento curricular. Inventariar e avaliar toda essa experiência pode contribuir para aprender com acertos e erros e incorporar práticas que propiciaram bons resultados.

A respeito da partilha de possibilidades sobre a constituição da parte diversificada do currículo, articulada à base comum, é importante que a Rede de Ensino e cada escola a ela pertencente tenham clareza das características e especificidades de cada contexto.

O coletivo de atores educativos (gestores, professores, estudantes e familiares) precisa estar imbuído do ideário do currículo estruturado com base no desenvolvimento de competências. Além disso, participar da revitalização dos dispositivos que norteiam a ação educativa no âmbito escolar, tais como o Projeto Político-Pedagógico.

Ao nos encaminharmos para as considerações finais, consideramos necessário enaltecer a postura da Secretaria de Educação e Cultura da Rede Municipal de Ensino, onde realizamos o estudo em tela, em relação ao processo de reorganização curricular em decorrência da implantação da BNCC no Municipio. Ao estabelecer parceria com a Universidade, buscando criar uma rede de apoio, o Município denota a seriedade com que conduz a gestão educacional. Corroboramos a posição de Imbernón (2013, p. 502), quando alude que:

Transformar, adaptar, modificar, revisar, refletir o currículo são palavras vazias se não exigirem o trabalho de todos, a colaboração entre os colegas, o intercâmbio entre iguais, a criação entre as instituições educativas de comunidades formadoras da prática.

Da mesma forma, é possivel observar que o engajamento, em nivel de mantenedora, reflete-se no compromisso assumido pelos gestores. As fragilidades evidenciadas pelos gestores, destacadas no decorrer do texto, de forma alguma desmerecem o empenho e a dedicação desses profissionais. Pelo contrário, indicam a importância do projeto educativo da Rede para cada um deles e o desejo de, ao reconhecer suas limitações, Interfaces da Educ., Paranaíba, v.11, n.32, p. 489 - 514, 2020 
disporem-se a superá-las coletivamente, por meio de um processo reflexivo auto e hetero formativo.

\section{Considerações finais}

As reflexões ora apresentadas evidenciam a complexidade da abordagem sobre o currículo escolar, tanto sob o ponto de vista legal e teórico quanto em seu aspecto constitutivo. A efetivação do que os dispositivos legais estabelecem acerca do currículo requer que os profissionais da educação, dentre eles os gestores, possuam espaços e tempos destinados à formação continuada. É necessário que esses profissionais conheçam e reflitam sobre tais dispositivos, articulando seus pressupostos a referenciais teóricos e a realidade do contexto escolar em que atuam.

A apropriação, pelos profissionais da educação, do ideário do currículo estruturado com base no desenvolvimento de competências, decorre das proposições da BNCC que estão estruturadas nesse princípio educativo. A isso se atrela a superação de uma visão reducionista acerca do currículo como mera listagem de conteúdos conceituais. Há de se pensar o currículo como um itinerário formativo que proporcionará aos estudantes o desenvolvimento de competências essenciais para que a aprendizagem ocorra tanto no espaço escolar quanto em outros ambientes educativos.

Por fim, salientamos que um dos limites do estudo que vislumbramos avançar no decorrer da pesquisa é a leitura de forma crítica, especialmente dos dispositivos legais, a fim de que sejam identificados os pressupostos curriculares veiculados e defendidos pelos mesmos. Além disso, com base nessa leitura, refletir se tais pressupostos condizem com o ideário educativo-formativo daquilo que, enquanto Rede de Ensino, almeja-se para as gerações presentes e futuras em termos de pessoa, sociedade e mundo. 


\section{Referências}

ABRAMOWICZ, Anete; CRUZ, Ana Cristina J.; MORUZZI, Andrea Braga. Alguns apontamentos: a quem interessa a Base Nacional Comum Curricular para a Educação Infantil?. Debates em Educação, v. 8, n. 16, p. 46-65, jul./dez. 2016.

ALVES, Nilda. Sobre a possibilidade e a necessidade curricular de uma base nacional comum. Revista E-curriculum, v. 12, n. 3, p. 1464-1479, out./dez. 2014.

ARROYO, Miguel G. Curriculo, território em disputa. 5.ed. Petrópolis, RJ: Vozes, 2013,

BARDIN, Laurence. Análise de Conteúdo. São Paulo: Edições 70, 2011.

BAUER, Martin W; GASKELL, George. Pesquisa qualitativa com texto, imagem e som: Um manual prático. Petrópolis: Vozes, 2003.

BELMONTE MACHADO, Roseli Belmonte; LOCKMANN, Kamila. Base Nacional Comum, escola, professor. Revista e-Curriculum, v. 12, n. 3, p. 1591 - 1613 out./dez. 2014.

BRASIL. Constituição da República Federativa do Brasil. Brasilia, DF: Senado Federal, 1988.

BRASIL. Lei $\mathbf{n}^{\circ} \mathbf{8 . 0 6 9}$, de 13 de julho de 1990. Dispõe sobre o Estatuto da Criança e do Adolescente e dá outras providências. Diário Oficial da União, Brasília, 16 de julho de 1990.

BRASIL. Lei $\mathbf{n}^{\circ}$ 9.394, de 20 de dezembro de 1996. Estabelece as diretrizes e bases da educação nacional. Diário Oficial da União, Brasília, 23 de dezembro de 1996.

BRASIL. Ministério da Educação. Conselho Nacional de Educação; Câmara de Educação Básica. Resolução $\mathbf{n}^{\circ}$ 5, de 17 de dezembro de 2009. Fixa as Diretrizes Curriculares Nacionais para a Educação Infantil. Diário Oficial da União, Brasilia, 18 de dezembro de 2009, Seção 1, p. 18.

BRASIL. Ministério da Educação. Conselho Nacional de Educação. Parecer CNE/CEB no 7/2010. Diretrizes Curriculares Gerais para a Educação Básica. Brasília, 2010a.

BRASIL. Ministério da Educação. Conselho Nacional de Educação; Câmara de Educação Básica. Resolução $\mathbf{n}^{\circ} \mathbf{7}$, de 14 de dezembro de 2010. Fixa Diretrizes Curriculares Nacionais para o Ensino Fundamental de 9 (nove) anos. Brasília, 2010b. 
BRASIL. Presidência da República. Casa Civil. Subchefia para assuntos jurídicos. Lei $\mathbf{n}^{\circ}$ 13.005, de 25 de junho de 2014. Aprova o Plano Nacional de Educação- PNE e dá outras providências, 2014.

BRASIL. Ministério da Educação. Base Nacional Comum Curricular. Brasília: MEC, 2017.

CARR, Wilfred. Una teoria para la educación: hacia una investigación educativa crítica. Madrid: Morata, 1996.

CARR, Wilfred; KEMMIS, Stephen. Teoria critica de la enseñanza: la investigación-acción en la formación del profesorado. Barcelona: Martinez Roca, 1998.

CARVALHO, Janete Magalhães; SILVA, Sandra Kretli da; DELBONI, Tânia Mara Zanotti Guerra Frizzera. A Base Nacional Comum Curricular e a produção biopolítica da Educação como formação de "capital humano". Revista e-Curriculum, v. 15, n. 2, p. 481-503, abr./jun. 2017.

CONTRERAS, José Domingos. Outras escolas, outra educação, outra forma de pensar o currículo. In: SACRISTÁN, José Gimeno (Org.) Saberes e incertezas sobre o curriculo. Porto Alegre: Penso, 2013, p. 459-477.

CÓSSIO, Maria de Fátima. Base Comum Nacional: uma discussão para além do currículo. Revista e-Curriculum, v. 12, n. 3, p. 1570 - 1590 out./dez. 2014.

CUNHA, Érika Virgílio Rodrigues da; LOPES, Alice Casimiro. Base nacional comum curricular no Brasil: regularidade na dispersão. Investigación Cualitativa, v. 2, n. 2, p. 23-35, 2017.

DOURADO, Luiz Fernandes. A formação de professores e a base comum nacional: questões e proposições para o debate. Revista Brasileira de Política e Administração da Educação, v. 29, n.2, p. 367-388, mai./ago. 2013.

ELLIOTT, John. El cambio educativo desde la investigación-acción. 3. ed. Madrid: Morata, 2000.

GODOY, Arilda S. Pesquisa qualitativa: tipos fundamentais. Revista Administração de Empresas. 1995, v. 35, n. 3, p. 20-29.

GONTIJO, Cláudia Maria Mendes. Base nacional Comum Curricular (BNCC): comentários críticos. Revista Brasileira de Alfabetização, v. 1, n. 2, p. 174-190, jul./dez. 2015. 
GOVERNO DO ESTADO RIO GRANDE DO SUL. CONSELHO ESTADUAL DE EDUCAÇÃO. Resolução no 345, de 12 de dezembro de 2018. Institui e orienta a implementação do Referencial Curricular Gaúcho.

HESS, Remi. Momento do diário e diário dos momentos. In: SOUZA, Elizeu Clementino; ABRAHÃO, Maria Helena Menna Barreto (Orgs.). Tempos, narrativas e ficções: a invenção de si. Porto Alegre: Edipucrs, 2006, p. 89-103.

IMBERNÓN, Francisco M. A formação dos professores e o desenvolvimento do currículo. In: SACRISTÁN, José Gimeno (Org.) Saberes e incertezas sobre o curriculo. Porto Alegre: Penso, 2013, p. 494-507.

KEMMIS, Stephen; McTAGGART, Robin. Cómo planificar la investigación-acción. Barcelona: Laertes Ediciones, 1992.

LIMAVERDE, Patricia. Base Nacional Comum: desconstrução de discursos hegemônicos sobre currículo mínimo. Revista Terceiro Incluido, v. 5, n. 1, p. 78-97, jan./jun. 2015.

LOPES, Alice Casimiro; MACEDO, Elizabeth. O pensamento curricular no Brasil. In: LOPES, Alice Casimiro; MACEDO, Elizabeth (Org.). Curriculo: debates contemporâneos. 3. ed. São Paulo: Cortez, 2010, p. 13-54.

LÜCK, Heloísa. O desenvolvimento de redes escolares. Revista Gestão em Rede, $n^{\circ} 23$, set/ 2000, p. 18-21.

MACEDO, Elizabeth. Base Nacional Curricular Comum: novas formas de sociabilidade produzindo sentidos para educação. Revista Ecurriculum, v. 12, n. 3, p.1530 - 1555 out./dez. 2014.

MACEDO, Elizabeth. Base Nacional Comum para Curriculos: direitos de aprendizagem e desenvolvimento para quem?. Educação \& Sociedade, v. 36, n. 133, p. 891-908, out./dez. 2015.

MACEDO, Elizabeth. Base Nacional Curricular Comum: a falsa oposição entre conhecimento para fazer algo e conhecimento em si. Educação em Revista, v. 32, n. 2, p. 45-68, abr./jun. 2016.

MARSIGLIA, Ana Carolina Galvão; PINA, Leonardo Docena; MACHADO, Vinícius de Oliveira; LIMA, Marcelo. A Base Nacional Comum Curricular: um novo episódio de esvaziamento da escola no Brasil. Germinal: Marxismo e Educação em Debate, v. 9, n. 1, p. 107-121, abr. 2017. 
MIRANDA, Marília G. de; RESENDE, A. C. A. Sobre a pesquisa-ação na educação e as armadilhas do praticismo. Revista Brasileira de Educação, 11 (33), 2006, p. 511-518.

MONCEAU, Guilles. Transformar as práticas para conhecê-las: pesquisaação e profissionalização docente. Educação e Pesquisa, São Paulo, 31 (3), 2005, p.467-482.

ORGANIZAÇÃO DAS NAÇÕES UNIDAS PARA A EDUCAÇÃO, A CIÊNCIA E A CULTURA - UNESCO. Declaração Mundial sobre Educação para Todos: satisfação das necessidades básicas de aprendizagem. Jomtien, 1990.

ORGANIZAÇÃO DAS NAÇÕES UNIDAS PARA A EDUCAÇÃO, A CIÊNCIA E A CULTURA - UNESCO. Declaração de Incheon - Educação 2030: Rumo a uma educação de qualidade inclusiva e à educação ao longo da vida para todos. UNESCO, 2015a.

ORGANIZAÇÃO DAS NAÇÕES UNIDAS PARA A EDUCAÇÃO, A CIÊNCIA E A CULTURA - UNESCO. Marco de Ação - Educação 2030: Rumo a uma educação de qualidade inclusiva e à educação ao longo da vida para todos. UNESCO, 2015b.

ORGANIZAÇÃO DAS NAÇÕES UNIDAS PARA A EDUCAÇÃO, A CIÊNCIA E A CULTURA (UNESCO). CONSED, AÇÃO EDUCATIVA. Educação para Todos: o Compromisso de Dakar. Brasília: Unesco, Consed, Ação Educativa, 2001.

ORGANIZAÇÃO DAS NAÇÕES UNIDAS - ONU. Declaração Universal dos Direitos Humanos, 1948.

ORGANIZAÇÃO DOS ESTADOS IBERO-AMERICANOS PARA A EDUCAÇÃO, A CIÊNCIA E A CULTURA (OEI). Metas Educativas 2021: a educação que queremos para a geração dos bicentenários. Documento final: síntese. Impressão no idioma português em 2012.Brasília, 2012.

PÁDUA, Elisabete M. M. Metodologia de pesquisa: Abordagem teóricoprática. Campinas: Papirus, 2004.

SACRISTÁN, José Gimeno. O que significa o currículo? In: SACRISTÁN, José Gimeno (Org.) Saberes e incertezas sobre o curriculo. Porto Alegre: Penso, 2013, p.16-35.

SÁ-SILVA, Jackson Ronie; ALMEIDA, Cristóvão Domingos, GUINDANI, Joel Felipe. Pesquisa documental: pistas teóricas e metodológicas. Rev. Bras. de História \& Ciências Sociais, n. I, p. 1-15, jul., 2009. 
SILVA, Ileizi Luciana Fiorelli; NETO, Henrique Fernandes Alves; VICENTE, Daniel Vitor. A proposta da Base Nacional Comum Curricular e o debate entre 1988 e 2015. Ciências Sociais Unisinos, v. 51, n. 3, p. 330-342, set./dez. 2015.

SOUSA, Jorge Luís Umbelino de. Currículo e projetos de formação: Base Nacional Comum Curricular e seus desejos de performance. Revista Espaço do Curriculo, v. 8, n. 3, p. 323-334, set./dez. 2015.

SÜSSEKIND, Maria Luiz. As (im)possibilidades de uma Base Comum Nacional. Revista e-curriculum, v. 12, n. 3, p. 1512-1529, out./dez. 2014.

ZABALA, Antoni; ARNAU, Laia. Como ensinar e aprender competências. Porto Alegre: Artmed, 2010.

ZEICHNER, Kenneth M.; DINIZ-PEREIRA, Júlio E. (2005). Pesquisa dos educadores e formação docente voltada para a transformação social. Cadernos de Pesquisa, São Paulo, 35 (125), 2005, p. 63-80. 